TITLE:

\title{
News : Director of the Tanzania National Parks, Lota Melamari, Visits Japan
}

$\operatorname{AUTHOR}(\mathrm{S})$ :

Nishida, Toshisada; Huffman, Michael A.

\section{CITATION:}

Nishida, Toshisada ... [et al]. News : Director of the Tanzania National Parks, Lota Melamari, Visits Japan. Pan Africa News 1997, 4(1): 7-8

ISSUE DATE:

1997-06

URL:

http://hdl.handle.net/2433/143348

RIGHT:

Copyright (C) Pan Africa News. 


\section{News}

\section{Director of the Tanzania National Parks, Lota Melamari, Visits Japan}

Mr. Lota Melamari, the Director-General of Tanzania National Parks visited Japan in April at the invitation of the Japan International Cooperation Agency (JICA). He arrived in Tokyo on the 30th of March and was escorted by Mrs. Sonoko Oshima of JICA who dedicatedly served as his coordinator and translator throughout the long journey.

Accompanied by Dr. Fumio Fukuda, the recent-JICA Ecology Expert to Mahale Mountains National Park, Tanzania, they visited JICA headquarters and the Japanese Environmental Agency on subsequent days.

On the 2nd of April, Mr. Melamari moved to Inuyama and visited with primatologist at the Kyoto University Primate Research Institute and toured the Japan Monkey Center with Ms. Miya Hamai of JMC and M.A. Huffman. On the 3rd of April, Melamari, Oshima and Huffman moved onto to Kyoto. After calling on Professor Hajime Ohigashi in the Graduate School of Agriculture, he went to the Laboratory of Human Evolution Studies in the Graduate School of Science, Kyoto University to meet with $T$. Nishida.

There an informal workshop on research in the Mahale Mountains commemorating the Director-General's visit was held. A number of Mahale researchers attended. Professor Kenji Kawanaka and Dr. Hiroyuki Takasaki came for the event from Okayama. Professor Junichiro Itani, pioneer of the work at Mahale also participated in the workshop. As the first presenter, Nishida discussed the general diversity of vegetation in the park, traditional land use patterns of the Batongwe people and brief remarks on the ecology of chimpanzees. Dr. Hiroshi Ihobe reported on his newest research results on population density of primate fauna in the park. Huffman reviewed his research on self-medicative behavior in chimpanzees and discussed future research plans. Kyoto University doctoral candidate, Ms. Linda Tuner discussed methodological aspects of her quantitative ecological study and presented a detailed classification of the vegetation types and major trees and woody vines used by the chimpanzees of $\mathbf{M}$ group. Finally, Ms. Noriko Itoh spoke on the results of her master's thesis study on the composition and density of chimpanzee food trees located along the trails which $\mathbf{M}$ group chimpanzees use frequently in their feeding activities.

In the evening, a welcome party hosted by Nishida for Mr. Melamari was held at a cozy little traditional Kyoto style restaurant, where he was joined by a select group of old Tanzania hands, Professors Junichiro Itani, Shunya Hino, Makoto Kakeya and more recent researchers to Tanzania Professors Hajime Ohigashi and Masaki Nishida.

In the late morning of April the 4th, Mr. Melamari presented a paper entitled "The Conservation and Park Management Policy in Tanzania" in the main auditorium of the Department of Biological Sciences Building. Although it was a holiday, many professors and post-graduate students from the University and elsewhere came to listen. After his 40 minute talk, there were lots of questions and lively discussion. In the afternoon, the DirectorGeneral paid a courtesy visit to the Center for African Area Studies of Kyoto University.

On the 5th of April, Mr. Melamari was taken to Arashiyama by Huffman where he had the opportunity to see Japanese monkeys in the misty mountains and view cherry blossoms at their peak. In the evening, the two joined Nishida and his wife at their home for a scrumptious Japanese home style dinner.

On the 6th of April, Mr. Melamari flew on south to the city of Kumamoto on the island of Kyushu. The purpose of his travel here was to inspect Mt. Aso National Park, best known for its namesake volcano with the world biggest caldera. On the 8th of April, he turned back north across the country to Kushiro in Hokkaido; the northernmost Island of Japan. There he observed the Kushiro Shitsugen, Japan's largest wetland are which harbors many kind of birds and waterfowl including the endangered Japanese crane. On the 10th of April, he returned to Tokyo. During his last days, he visited some Japanese conservationists, visited with JICA again and participated in the regular meeting of the Savanna Club, one of the important Japanese donors to TANAPA. 
After an intensive and we hope non-stop enjoyable tour, Mr. Melamari left Tokyo for Tanzania on the 12th of April. He was well received by all that he met and we hope that his visit was both constructive and memorable.

Toshisada Nishida

Graduate School of Science, Kyoto University and Michael A. Huffman

Primate Research Institute, Kyoto University

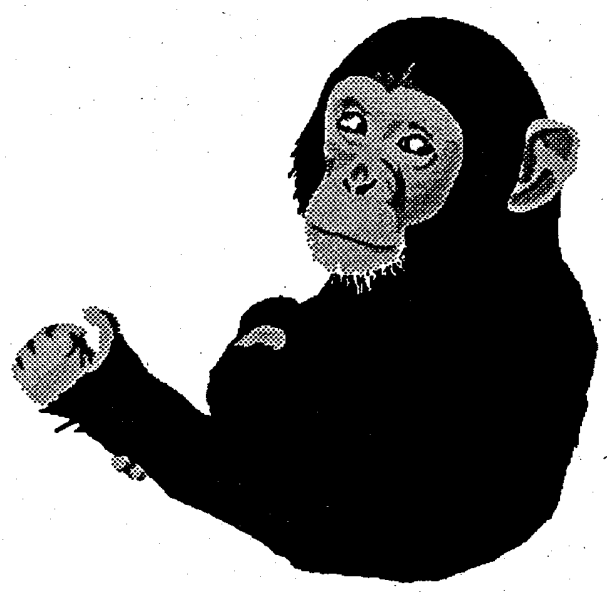

Illustration by Michio NaKamura 